Letter to Editor

\title{
COMPARISON BETWEEN GENERIC DRUGS AND BRAND NAME DRUGS FROM BIOEQUIVALENCE AND THERMOEQUIVALENCE PROSPECTIVE
}

\author{
MOSAB ARAFAT ${ }^{1 *}$, ZAHAA AHMED ${ }^{1}$, OSAMA ARAFAT ${ }^{2}$ \\ ${ }^{1}$ College of Pharmacy, Al Ain University of Science and Technology (AAU), P. 0. Box: 64141 Abu Dhabi, UAE. ${ }^{2}$ Department of Pharmacy, \\ King Fahad Specialist Hospital (KFSH), 32253 Dammam, KSA
}

Email: mousab.arafat@otago.ac.nz

Received: 28 Mar 2017 Revised and Accepted: 09 May 2017

\begin{abstract}
ABSTACT
The belief that generic drugs are inferior to brand name drugs has been always under debate. Especially since the price of generic drugs is generally far cheaper than brand-name drugs. Although, this is because of waiving the preclinical studies and clinical trials for the generic drug, the quality, and purity of materials used for generic drug preparation is still arguable. Thus, the objective of this overview was to find out the tolerable deviations between generic and brand name drugs which should not alter the pharmacology. Using inactive additives in the generic drug different than in the brand name drug, such as binders, glidants, diluents, anti-adherents, disintegrants or polymer carrier material and filler should not change the drug bioavailability and pharmacokinetic parameters as long as both products using the identical active ingredient(s) in equivalent amounts. Even if both drug products are bioequivalent to each other in terms of active ingredient, they are not in terms of inactive ingredients. Hence, the probability of unexpected adverse drug reaction and allergies from the generic formulation are possible, especially, when people react sensitive toward specific component. Therefore, the occasional negative response occurring upon the switch from brand-name drug to the generic drug can be attributed to intra-and inter-patient variations toward inactive ingredients. Variations toward inactive ingredients can be obtained experimentally by utilizing a proper thermoanalytical technique. As a result, thermoequivalence of generic drugs to brand name drugs can be determined based on thermal information obtained from both products. In conclusion, thermoequivalence study can be a useful tool to demonstrate any possible variation between the inactive ingredients of both products.
\end{abstract}

Keywords: Generic drug, Brand name drug, Thermoequivalence, Bioequivalence, Active materials, Inactive materials

(C) 2017 The Authors. Published by Innovare Academic Sciences Pvt Ltd. This is an open access article under the CC BY license (http://creativecommons.org/licenses/by/4.0/] DOI: http://dx.doi.org/10.22159/ijpps.2017v9i6.18735

\section{INTRODUCTION}

Commercially, medications are either brand name drugs or generic drugs. Brand name drugs are also called innovator drug and they are these type of medications which are patented, manufactured and licensed for the first time. In contrast, generic drugs are these type of medications which are bioequivalent to the brand name drugs and have identical active ingredients but produced after patent expirations by another manufacturer [1]. Generic drugs are similar to brand-name drugs in terms of identity, strength, quality, purity, safety, potency, uses and treatment. According to US Food and Drug Administration (FDA) standards, generic drugs must have identical active ingredient, dosage form, strength, efficacy, route of administration, drug bioavailability profile and pharmacokinetic (PK) parameters similar to the brand name drug [2].

Similarly, modified release formulation of the generic drug must be bioequivalent to a modified release formulation of brand name drugs such as controlled release drug preparations $[3,4]$. However, some variations in the medication formulation are accepted such as purity, inactive substances variety, color, size, shape, packaging, and labeling as long as they have no interferences. Using different inactive substances in the generic drug preparation than in the brand name drug is acceptable for the generic drug by FDA. Though, these inert additives such as fillings, flavorings, glidants, lubricants, disintegrating agents and preservatives must be listed as safe and interference free materials in the drug composition according to the FDA safety regulations. Besides, generic drugs must follow the expiry date of the brand name drug [5].

Economically, generic drugs are less costly in production than brand name drugs and therefore, they are cheaper in the market [2]. Previous studies concluded that saving up to 10 billions of dollars every year can be achieved upon replacing brand name drug by generic drugs [6]. Another economical study reported that saving of up to 158 billions of dollars every year can be achieved [7]. This can explain the reason behind the preference of choosing generic drugs over brand name drugs in the health sector, such as hospitals, healthcare centers and health insurances [8]. Overall, generic drugs are less costly due to the avoidance of repeating many costly requirements to place brand names drugs on the market such as, preclinical studies, clinical trials, advertising, marketing, and promotion. As a result, at least $80 \%$ of prescriptions filled in the US are for generic drugs according to FDA.

Since an abbreviated system (abbreviated new drug application) that designed by the 1984 Drug Price Competition and Patent Term Restoration Act (Hatch-Waxman Act) in the US is applicable for approval of generic drugs of all drugs approved after 1962 [9], hence, preclinical studies and clinical trials are not required for generic drugs FDA approval [6]. This would mainly contribute to lower the cost of generic drug production [10-11].

Table 1: Regulatory standards required by brand name drugs but not generic drugs [12]

\begin{tabular}{lll}
\hline Regulatory standards & Brand name drugs & Generic drugs \\
\hline Scientific studies & Full & Bioequivalence studies \\
New active moiety & Required & Not Required \\
New indication & Required & Not Required \\
New dosage form & Required & Limited \\
New strength & Required & Not Required \\
Patent & Required & Not Required \\
Exclusive marketing & Required & Not Required \\
\hline
\end{tabular}


Table 1 shows the differences between brand name drugs and generic drugs in terms of regulatory standards requirement. Generic drugs can be launched in the market after the patent expiration date of brand name drug takes a place. Thus, for generic drug FDA Abbreviated New Drug Application (ANDA) is used, in which many requirements are waived in comparison to new drug applications (NDA) $[12,13]$.

Historically, despite providing more requirements for the drug to be accepted by the 1962 Kefauver-Harris Drug Amendments (KHDA), the US regulators did not guarantee the safety of new drugs for human consumption. In the 1980's, during the AIDS crisis, the Orphan Drug Act (ODA) was enacted in 1983 to enhance medicines development for the treatment of diseases attacking small communities. In 1984, the Hatch-Waxman Act (HWA) was enacted by the US Congress for the marketing of generic drugs. In 2010, the Biologics Price Competition and Innovation Act of 2009 (BPCI Act) was stated into law. This was an amendment to the Public Health Service Act to have an abbreviated approval method for biological products that are highly biosimilar to a FDA-approved biological product with the aim to save time, money and avoiding human or animal testing [14].

For the approval of any generic drug, bioequivalence (BE) data that match the BE data of the brand name drug is mandatory as this essentially controls the quality, efficacy, and safety of generic drugs. In BE studies, pharmacokinetics parameters and drug bioavailability of both medication using the same route of administration and the same amount of drug that given to the same number of healthy volunteers under similar experimental conditions must be comparable [8-10]. Development of sensitive and validated analytical method such as high-performance liquid chromatography (HPLC) or liquid chromatography mass spectrometry (LC/MS) for measurement of both drug concentrations in plasma is critical to get precise and accurate $\mathrm{PK}$ parameters and proper BE results. The development of some of these analytical methods can be challenging as it depends on the amount and chemical stability and the biopharmaceutics classification system (BCS) of drug used [15-18].

In order to achieve comparable BE data, generic drugs must be identical to brand-name drugs in terms of active ingredient, strength, dosage form, route of administration and therapeutic uses. They must meet the same batch requirements for identity, strength, purity, safety and quality, whereas manufacturing process must follow FDA's regulations and standards for good manufacturing practice [8].

According to FDA, all generic drug types even a drug with narrow therapeutics index, must be bioequivalent to brand-name drugs within an acceptance interval of 80 to $125 \%$ of the AUC (area under the concentration-time curve), which reflects the rate and extent of drug absorption at a $90 \%$ confidence interval [10]. However, some drugs with narrow therapeutics index in some countries are not interchangeable such as digoxin and phenytoin [10]. In Europe, the legal requirements for licensing pharmaceutical products is more demanding than US, since each state has its own authority in addition to the European Medicines Agency [19, 20]. Although BE parameters for generic drugs are similar to those required by US, they are more tightened for drugs with narrow therapeutics index as the BE acceptance interval is $90.00-111.11 \%$ as well as different assessment requirements for highly variable drug products [21, 22].

A number of studies have demonstrated that replacing brand name drugs by generic drugs has no differences [20]. In contrast, adverse drug reaction was reported to be found in some patients during a trail study on replacing a brand name drug of extended carbamazepine release formulation with an equivalent generic drug, although both medications were within BE acceptable range [21]. Therefore, bioequivalence does not always correspond to therapeutic equivalence. Even though BE studies can be considered as a test for pharmacokinetics, pharmacodynamics, or comparative clinical trials depending on whether the drugs work systemically or locally [22]

Even the active ingredient does not differ between brand name drug and generic drug, other excipients, may be different and they may have contradicted effect [22] since a wide variety of excipients can be used in drug formulation [23-26]. Therefore, differences in excipients between brand-name drugs and their generic counterparts can cause problems [27] even with rational drug use [28]. For example, an allergic reaction was reported upon switching the brand name drug furosemide to the generic furosemide preparation containing croscarmellose sodium in the formulation compositions [29].

Croscarmellose is an excipient with multifunctional uses, such as suspending agent, binding agent, glidant and anti-adherent material [29]. Similarly, another allergic reaction was reported for lactoseintolerant patients upon switching from an anti-arrhythmic brandname drug to the generic drug containing lactose in the formulation [30]. Furthermore, drug relapses in some patients were reported upon switching brand name drug Prozac to the generic fluoxetine [31]. The occurrence of unexpected effects in some generic drug formulations could be attributed to various factors, such as intra-and inter-patient variations toward additive materials, patient medical conditions [32], or alteration in the drug synthesis steps [33].

Among various analytic methods, thermal analysis is a wellestablished, simple and sensitive evaluation technique in pharmaceutical research and production nowadays. Differential scanning calorimetry (DSC) or thermal gravimetric analysis (TGA) can be used in separated or combined measurements. Fig. 1 shows representative TGA and DSC traces with potential thermal transitions that can occur when a sample is scanned within a predetermined temperature range and a set heating ratio.

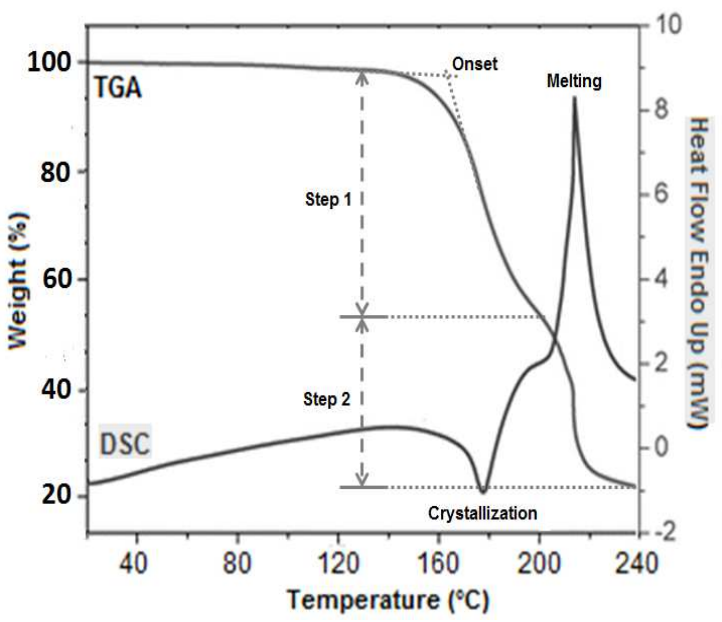

Fig. 1: Representative thermal curves of simultaneous DSC-TGA measurement 
TGA analysis provides quantitative and qualitative information in form of changes in weight or energy measured as a function of time and temperature, which reflects the physical and chemical properties of the sample. In the DSC measurement, the changes in heat capacity are monitored while the sample is subjected to a controlled temperature program using a reference material. This allows the detection of changes in the heat flow such as glass and melting transition glass transitions, as well as crystallization and the associated entropies used to calculated crystallinity.

Thermal analysis has been used most widely in the pharmaceutical field to determine the identity and purity of materials. The ability to use the degradation temperature as unique characteristic to identify drugs was presented for anti-diabetic drugs, namely pioglitazone hydrochloride, rosiglitazone maleate, glibenclamide and glimepiride [34]. Thus, thermal analysis is a valuable measurement for quality control not only determining the melting temperature but also evaluating the water and ash content derived from the TGA curve as shown for terazosin hydrochloride [35] and the antihypertensive drugs Telmisartan and Cilazapril [36].

Furthermore, thermal analysis has proven to be a powerful tool in elucidating as to whether a drug and its carrier may interact when fused together or they may be stable [37] and consequently, facilitates the selection of a formulation that consists of the optimal drug carrier ratio [38]. For example, the drug-polymer interactions of naproxen and various polyethylene glycols have been investigated using DSC [39]. The compatibility of drugs with excipients is clearly reflected by intensities and shifts in thermal traces. Such potential changes were investigated for glibenclamide [40] and ralidoxime chloride using TGA and DSC, respectively [41].

Since adverse drug reaction or allergies might arise from generic formulations, thermal analysis can also be a useful tool in providing information not only on the drug but also on inactive ingredients in brand-name versus generic drugs. Potential interactions can be detected for example by a change in drug degradation temperature or number/intensities of degradation steps in the TGA traces. Changes in the DSC measurements can arise in form of different crystallization or melting temperature as well as the related entropy and crystallinity.

\section{CONCLUSION}

Even though generic drugs must be bioequivalent to brand-name drugs in terms of active ingredients, this does not mean that they are bioequivalent to each other in terms of inactive ingredients. Hence, the probability of unwanted medication reaction is possible. This might actually happen upon switching from brand name drug to generic drug. This could be attributed to intra-and inter-patient variations toward inactive ingredients. Variations toward inactive ingredients can be obtained experimentally by utilizing a proper thermoanalytical technique as thermo equivalence study can be a useful tool to demonstrate any possible variation between the inactive ingredients of both products.

\section{ACKNOWLEDGEMENT}

We are thankful to Al Ain University of Science and Technology for providing a support and fund for conducting this study.

\section{AUTHORS' CONTRIBUTION}

Arafat $\mathrm{M}$ researched and wrote this overview. Arafat $\mathrm{O}$ and $\mathrm{Ahmed} \mathrm{Z}$ provided guidance, critical review, and revision. All authors read and approved the final version of this comparison study.

\section{CONFLICT OF INTERESTS}

\section{Declared none}

\section{REFERENCES}

1. Davit BM, Nwakama PE, Buehler GJ, Conner DP, Haidar SH, Patel DT, et al. Comparing generic and innovator drugs: a review of $12 \mathrm{y}$ of bioequivalence data from the United States food and drug administration. Ann Pharmacother 2009; 43:1583-97.
2. Dong BJ, Hauck WW, Gambertoglio JG, Gee L, White JR, Bubp JL, et al. Bioequivalence of generic and brand-name levothyroxine products in the treatment of hypothyroidism. JAMA 1997;277:1205-13.

3. Arafat M. Approaches to achieve an oral controlled release drug delivery system using polymers: a recent review. Int J Pharm Pharm Sci 2015;7:16-21.

4. Khatavkar UN, Kumar KJ, Shimpi SL. Novel approaches for the development of oral controlled release compositions of galantamine hydrobromide and paroxetine hydrochloride hemihydrate: a review. Int J Appl Pharm 2016;8:1-6.

5. Kesselheim AS, Misono AS, Lee JL, Stedman MR, Brookhart MA, Choudhry NK, et al. Clinical equivalence of generic and brandname drugs used in cardiovascular disease: a systematic review and meta-analysis. JAMA 2008;300:2514-26.

6. Dentali F, Donadini MP, Clark N, Crowther MA, Garcia D, Hylek $\mathrm{E}$, et al. Brand name versus generic warfarin: a systematic review of the literature. Pharmacotherapy 2011;31:386-93.

7. Dicken JE. Drug pricing: research on savings from generic drug Use. GAO US Government Accountability Office; 2011;1-19. Available from: http://www.gao.gov/products/GA0-12-371R. [Last accessed on 20 Feb 2017]

8. FDA Fact sheet: What's involved in reviewing and approving generic drugs applications? Available from: https:// www.fda.gov/Drugs/ResourcesForYou/Consumers/BuyingUsi ngMedicineSafely/UnderstandingGenericDrugs/ucm506040. htm [Last accessed on 20 Feb 2017]

9. Moore N, Berdaï D, Bégaud B. Are generic drugs really inferior medicines? Clin Pharmacol Ther 2010;88:302-4.

10. Wilner AN. Therapeutic equivalency of generic antiepileptic drugs: results of a survey. Epilepsy Behav 2004;5:995-8.

11. McCormack J, Chmelicek JT. Generic versus brand name: the other drug war. Can Fam Physician 2014;60:911.

12. Stegemann S, Klebovich I, Antal I, Blume HH, Magyar K, Németh $\mathrm{G}$, et al. Improved therapeutic entities derived from known generics as an unexplored source of innovative drug products. Eur J Pharm Sci 2011;44:447-54.

13. Nadler HL, Degraft-Johnson D. Demystifying FDA's 505(b), drug registration process. Regulatory Focus; 2009. p. 25-30.

14. Dunne S, Shannon B, Dunne C, Cullen W. A review of the differences and similarities between generic drugs and their originator counterparts, including economic benefits associated with usage of generic medicines, using Ireland as a case study. BMC Pharmacol Toxicol 2013;14:2-19.

15. Arafat M, Golocorbin KS, Mikov M. The measurement of cefotaxime sodium in rat plasma after oral administration: a sensitive HPLCUV method. Int J Pharm Pharm Sci 2015;7:343-46.

16. Arafat M. Simple HPLC validated method for determination of diltiazem hydrochloride in Human. Int J Pharm Pharm Sci 2014;6:213-16

17. Arafat M, Zahaa A, Mikov M. Determination of nifedipine in rat plasma using HPLC-UV detector: a simple method for pharmacokinetics and oral bioavailability studies. Int J Pharm Pharm Sci 2016;8:98-102.

18. Arafat M. The effect of intestinal bile on the stability of lipidbased vesicular system used as oral drug carriers. Global Blood Therapeutics 2016;2:1-2.

19. Kesselheim AS, Bykov K, Avorn J, Tong A, Doherty M, Choudhry NK. Burden of changes in pill appearance for patients receiving generic cardiovascular medications after myocardial infarction: cohort and nested case-control studies. Ann Intern Med 2014;161:96-103.

20. Thakkar KB, Billa G. The concept of: Generic drugs and patented drugs vs. brand name drugs and non-proprietary (generic) name drugs. Front Pharmacol 2013;4:113.

21. WHO. Guidance on INN. Essential medicines and health products; 2013a. Available from: www.who.int/medicines/ services/inn/innguidance/en/index. html. [Last accessed on 20 Feb 2017]

22. Mukti AA, Jannah F, Nurrochmad A, Lukitaningsih E. Development and validation method for quantitative determination of ciprofloxacin in human plasma and its application in bioequivalence test. Asian J Pharm Clin Res 2016;9:89-95. 
23. Cameron A, Mantel-Teeuwisse AK, Leufkens HG, Laing RO. Switching from originator brand medicines to generic equivalents in selected developing countries: how much could be saved? Value Health 2012;15:664-73.

24. Arafat M, Kirchhoefer C, Mikov M. Mixed micelles loaded with bile salt: an approach to enhance intestinal transport of the BCS class III drug cefotaxime in rats. Eur J Drug Metab Pharmacokinet; 2016. p. 1-11.

25. Golocorbin-Kon S, Mikov M, Arafat M, Lepojevic Z, Mikov I, Sahman-Zaimovic M, et al. Cefotaxime pharmacokinetics after oral application in the form of $3 \alpha, 7 \alpha$-dihydroxy-12-keto-5 $\beta$ cholanate microvesicles in rat. Eur J Drug Metab Pharmacokinet 2009;34:31-6.

26. Arafat M. Bilosomes as a drug delivery system, University of Otago; 2012. Available from: http://hdl.handle.net/ 10523/2157. [Last accessed on 20 Feb 2017].

27. Mayer T, May TW, Altenmuller DM, Sanmann M, Wolf P. Clinical problems with generic antiepileptic drugs. Clin Drug Invest 1999;18:17-26

28. Miraci M, Haloci E, Toto B. The evaluation of the rational use of some drugs in albania. Asian J Pharm Clin Res 2015;8:90-4.

29. Mumoli N, Cei M, Luschi R, Carmignani G, Camaiti A. Allergic reaction to croscarmellose sodium used as excipient of a generic drug. Q J Med 2011;104:709-10.

30. Gallelli L, Palleria C, De Vuono A, Mumoli L, Vasapollo P, Piro B, Russo E. Safety and efficacy of generic drugs with respect to brand formulation. J Pharmacol Pharmacother 2013;4:S110-4.

31. Shields BJ, Nahata MC. Efficacy of brand-name vs. generic fluoxetine. Perspect Psychiatr Care 2003;39:122-4.

32. Arafat M, Salam A, Arafat O. The association of type 2 diabetes with obesity and other factors: in the multinational community. Int J Pharm Pharm Sci 2014;6:257-60.
33. Blier P. Brand versus generic medications: the money, the patient and the research. J Psychiatry Neurosci 2003;28:167-8.

34. Attia AK, Ibrahim MM, El-Ries MA. Thermal analysis of some antidiabetic pharmaceutical compounds. Adv Pharm Bull 2013;3:419-24.

35. Attia AK, Abdel-Moety MM. Thermoanalytical investigation of terazosin hydrochloride. Adv Pharm Bull 2013;3:147-52.

36. Saber RA, Attia AK, Salem WM. Thermal analysis study of antihypertensive drugs telmisartan and cilazapril. Adv Pharm Bull 2014;4:283-7.

37. Singh S, Wu C, Williams PT. Pyrolysis of waste materials using TGA-MS and TGA-FTIR as complementary characterisation techniques. J Anal Appl Pyrolysis 2012;94:99-107.

38. Wendlandt WW, George TD. The thermal decomposition of metal complexes-I: Thermogravimetric and differential thermal analysis. J Inorg Nucl Chem 1961;21:69-76.

39. Dordunoo SK, Ford JL, Rubinstine MH. Solidification studies of polyethylene glycols, gelucire $44 / 14$ or their dispersions with triamterene or temazepam. J Pharm Pharmacol 1996;48:782-9.

40. Oliveira GGG, Ferraz HG, Matos JSR. Thermoanalytical study of glibenclamide and excipients. J Therm Anal Calorim 2005;79:267-70.

41. Gutch PK, Jitendra S, Alankar S, Anurekha J, Ganesan K. Thermal analysis of the interaction between 2-PAM chloride and various excipients in some binary mixtures by TGA and DSC. J Therm Anal Calorim 2013;111:1953-8.

\section{How to cite this article}

- Mosab Arafat, Zahaa Ahmed, Osama Arafat. Comparison between generic drugs and brand name drugs from bioequivalence and thermoequivalence prospectives. Int J Pharm Pharm Sci 2017;9(6):1-4. 